\title{
Demystifying construction project time-effort distribution curves: a BIM and non-BIM comparison
}

\author{
Weisheng $\mathrm{LU}^{1}$, Ada FUNG ${ }^{2}$, Yi PENG ${ }^{3}$, Cong $\mathrm{LIANG}^{4}$, and Steve ROWLINSON ${ }^{5}$
}

\begin{abstract}
:
MacLeamy's time-effort distribution curves are amongst the most oft-cited sources for researchers interested in mainstreaming Building Information Modeling (BIM) implementation in the architecture, engineering, and construction (AEC) industry. Succinctly, the curves offer a clever answer to the question: How can BIM benefit AEC processes? However, despite their significant theoretical and practical value, little previous research has been conducted to elaborate the time-effort distribution curves of any real-life projects. This research aims to demystify the time-effort distribution curves through comparison of a representative BIM project and a non-BIM project. Applying a set of innovative approaches, the actual time-effort distribution curves of two public housing construction projects in Hong Kong are produced and analyzed in-depth. The curves vividly show that BIM implementation increases the effort spent at design stage - that is, throughout the architecture and engineering processes, - but the extra effort pays off at the building stage. Further, the curves are found to be a useful graphical analytic tool for other purposes, such as adjusting the fee structure amongst AEC processes and informing improved BIM adoption.
\end{abstract}

Keywords: Building Information Modeling (BIM); Time-effort distribution curve; Construction processes; Construction management; Construction sector

\footnotetext{
${ }^{1}$ Associate Professor, Dept. of Real Estate and Construction, Faculty of Architecture, The University of Hong Kong, Pokfulam, Hong Kong. Email: wilsonlu@hku.hk

2 Deputy Director (Development \& Construction), Hong Kong Housing Authority, Kowloon, Hong Kong.

3 Post-Doctor Fellow, Dept. of Real Estate and Construction, Faculty of Architecture, The University of Hong Kong, Pokfulam, Hong Kong.

4 PhD candidate, Dept. of Real Estate and Construction, Faculty of Architecture, The University of Hong Kong, Pokfulam, Hong Kong.

5 Professor, Dept. of Real Estate and Construction, Faculty of Architecture, The University of Hong Kong, Pokfulam, Hong Kong.
} 


\section{Introduction}

The time-effort distribution curves introduced by MacLeamy (2004) tend to be cited by most keynote speakers at Building Information Modeling (BIM) conferences. As shown in Fig. 1, MacLeamy's time-effort distribution curves have four components: (1) a curve indicating the ability to impact cost and functional capability as a project progresses; (2) a curve showing the cost of design change; the later the change, the more the cost it incurs; (3) a curve indicating the distribution of design effort in traditional architecture, engineering, and construction (AEC) processes; and (4) a curve showing the design effort distribution in BIM-enabled AEC processes. Collectively, these curves offer a clever answer to the question: How can BIM benefit the AEC industry?

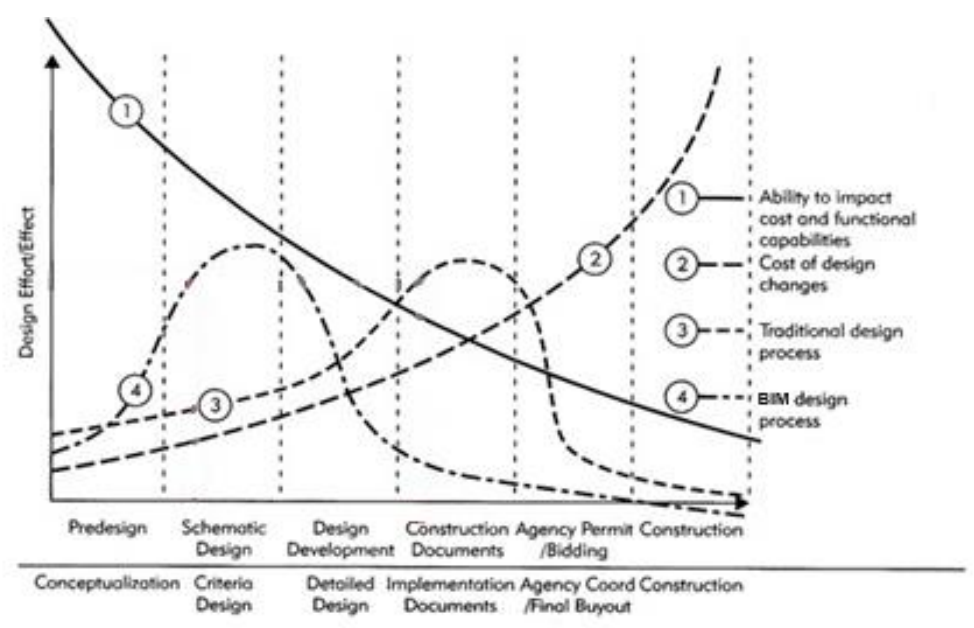

Fig. 1. The time-effort distribution at design stage for BIM-enabled and traditional AEC processes Source: Adapted from MacLeamy (2004)

The AEC industry is notorious for its low productivity, backwardness, and wasted effort. In 2004, the US Construction Industry Institute estimated that $57 \%$ of all effort spent on construction in the US was non-value-added and therefore wasted (Eastman et al., 2008). MacLeamy (2004) attributes the problems to a fatally flawed system; under the current design, bid, and build (DBB) system, professionals such as architects, engineers, surveyors and contractors are separately contracted to perform a parcel of the work. Although under the same umbrella of a project, they do not necessarily interact throughout the project lifecycle, do not always work together efficiently and can, in fact, have competing interests (MacLeamy, 2004). This silo mentality leads to the well-known problems of the 
fragmentation and discontinuity in the AEC industry (Lu and Li, 2011).

With the help of his time-effort distribution curves, MacLeamy illustrates how these issues can be addressed through implementation of BIM in AEC processes. Traditional AEC processes in the DBB procurement system involve the investment of separate efforts by designers and contractors in construction documentation and management (Curve 3), while BIM-enabled processes encourage more effort (e.g. early collaboration and open information sharing) from the entire project team during the schematic design and design development phases (Curve 4). MacLeamy argues that BIM implementation should advance design effort to the schematic design and design development phases, and that this slight change will ameliorate the ingrained problems associated with the DBB system and lead to productivity improvement.

However, BIM does not fit the current prevailing procurement systems (e.g. DBB) quite well. Many researchers and even industry practitioners emphasize that BIM needs new processes, such as integrated project delivery (IPD) (Eastman et al., 2008; Wu and Issa, 2014). IPD is defined by AIA (2010) as a "method distinguished by a contractual agreement between a minimum of the owner, design professional, and builder where risk and reward are shared and stakeholder success is dependent on project success." It is found that BIM emphasizes more on the tools, processes and technologies that are facilitated by the digital platform, while IPD stresses more on the contractual agreement that can brings the stakeholders together at the early stage of building. BIM is one of the core elements around which IPD is structured (Construction Specifications Institute, 2011). Therefore, it is not surprising that BIM and IDP share similar principles. In addition, there are many derivatives of MacLeamy (2004) developed by different organizations or researchers to emphasize the impact of IPD, for example by ENR (2012). However, this study only focuses on the impact of BIM with regards to MacLeamy's curve.

Owing to its intuitiveness, many researchers have used MacLeamy's set of curves to illustrate the benefits of BIM with a view to mainstreaming its implementation in the AEC industry. However, to 
the best of our knowledge, no research has yet been conducted to elaborate the time-effort distribution curve of a construction project. Nor has previous research been undertaken to produce an actual time-effort distribution curve. While Aranda-Mena et al. (2009) present two interesting versions of MacLeamy's theoretical curves, their approach is largely qualitative; they solicited quality responses to the perceived 'effort distribution' required to create BIM.

Demystifying the time-effort distribution curves of construction projects has significant theoretical and practical implications. For example, Back to Paulson (1976), the interrelationships between engineering design, construction, and operation costs for a facility have been investigated and it was found that engineering and design play a great role but actual expenditures at that stage are relatively small. Recently, Aranda-Mena et al. (2009) suggest that a clear understanding of these curves would have direct application to the variation of fee structures. The spent effort distributed over time can be calculated to draw the famous S-curve, which has attracted numerous researchers (Skitmore, 1988; Kaka, 1999; Barraza et al., 2000; Chao and Chien, 2009; Cheng et al., 2011) and remains a popular research topic given its capability to inform construction expenditure flow. Although stakeholders are increasingly seeing the benefits of BIM, the question of how it can be efficiently implemented in real-life projects remains controversial. Time-effort distribution curves, however, can graphically indicate the different cost and saving patterns caused by BIM adoption, which in turn can inform stakeholders as to improved BIM implementation.

The aim of this research is therefore to demystify the time-effort distribution curves of a construction project with BIM support (hereinafter the BIM project) by comparing them with the curves of a construction project without BIM support (hereinafter the non-BIM project). Subsequent to this introductory section, the research methodology is introduced in Section 2. Here, a set of innovative approaches devised to produce the time-effort distribution curve of a project from time sheets and payment records are described. Case studies of two housing projects, one with BIM implementation and the other without a BIM element, are introduced in Section 3, and a thorough discussion of the analytic results is conducted. Section 4 further explores the implications of the time-effort distribution 
curves for management practice, while Section 5 draws conclusions and proposes directions for further research.

\section{Methodology}

In order to demystify time-effort distribution curves, time-effort data from real-life projects must be collected and processed. Although the rationale underlying the methodology is straightforward, the curves must be produced and analyzed by following a series of analytical processes (see Fig. 2).

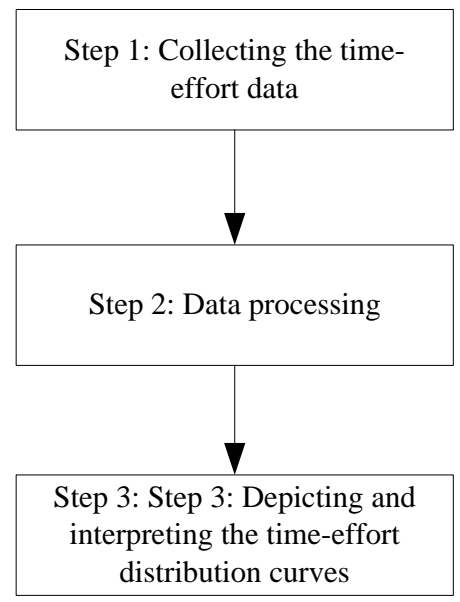

Fig. 2. Processes for demystifying the time-effort distribution curve

\section{Step 1: Collecting the time-effort data from real-life projects}

The terms 'time' and 'effort' must be defined explicitly with regards to the time-effort distribution curve. Here, 'time' means the time period during a project process. It can refer to intervals of days, weeks or months, depending on the level of detail at which the project process is researched (Lu et al., 2013). In undertaking a project, different participants such as clients, architects, engineers, consultants, contractors and laborers will input their 'effort' at different stages of the project lifecycle. The effort can be seen as the amount of 'chargeable service time" rendered by individual participants. To capture the effort contributed to a project by different participants, a bar chart vehicle has been designed (see Fig. 3[a]). By vertically aggregating the efforts as recorded in Fig. 3(a) and linking the data points, a time-effort distribution curve can be drawn (See Fig. 3[b]). 
Time-Effort of a project

Project Serial No.:

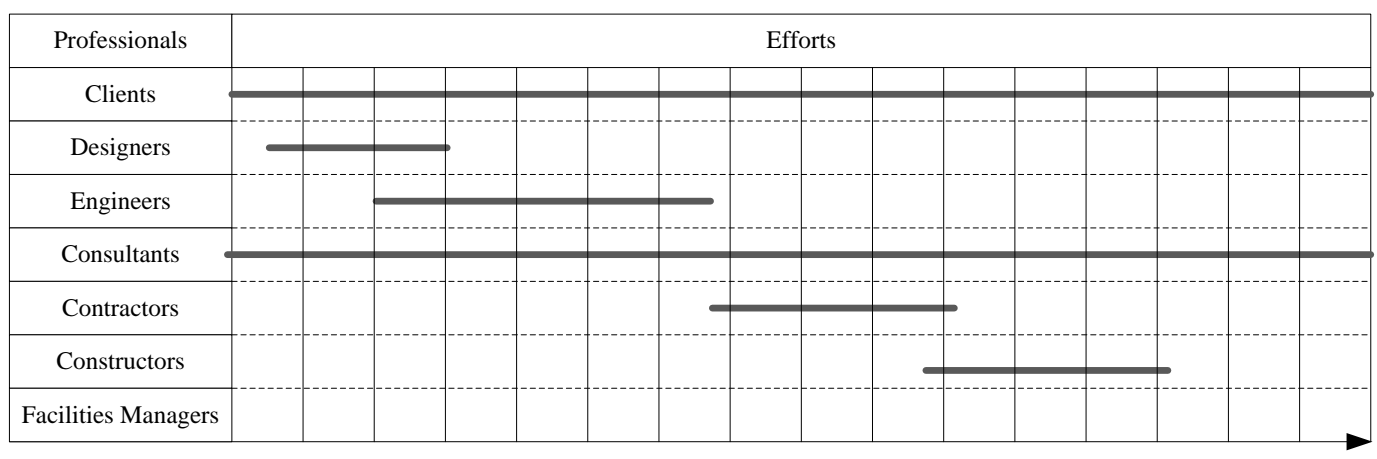

(a)

Time (Day/Week/Month)

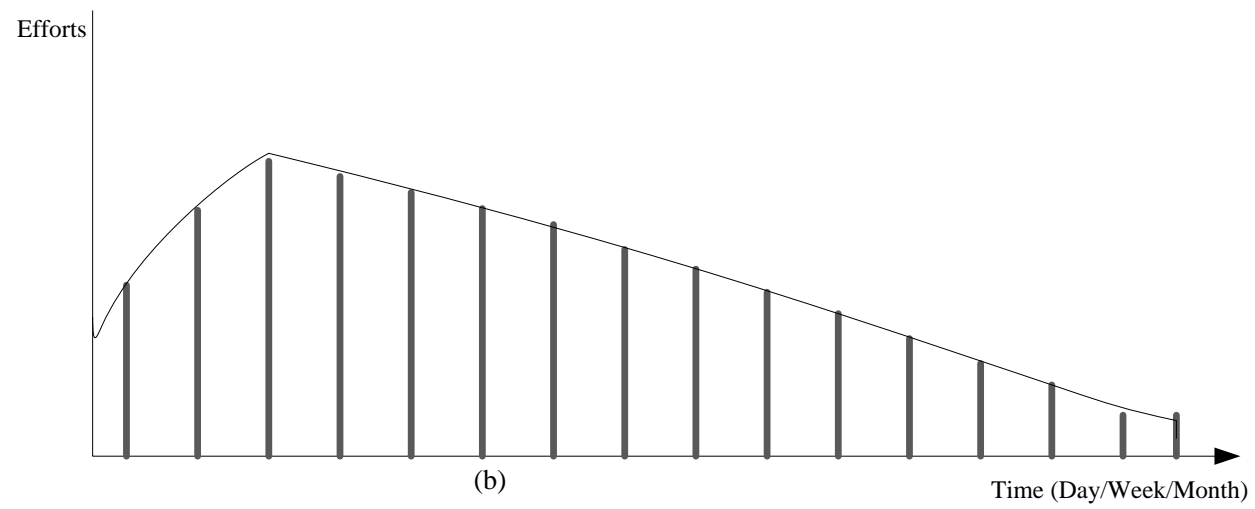

Fig. 3. An innovative approach to capture the time-effort distribution curve for a project 
However, to incorporate the aforementioned two sets of information ('time' and 'efforts') in a simple manner, the above method needs adjustment: the effort, or 'chargeable service time', cannot simply be aggregated as different participants will charge different fees for their efforts rendered. Complicating the issue, according to Smith and Tardif (2009), the architect's moment of inception is hard to determine. Thus, here the term 'priced efforts (PE)' is introduced as shown in Equation (1).

$$
P E=\left[\begin{array}{ccc}
P E_{11} & \cdots & P E_{1 t} \\
\vdots & \ddots & \vdots \\
P E_{n 1} & \cdots & P E_{n t}
\end{array}\right]
$$

where $P E_{i j}$ represents the priced efforts from party $i$ in time $j$, the differences in parties' efforts having been priced through market mechanisms such as competitive bidding and tendering, bargaining, negotiating, and subcontracting. Specifically, $\mathrm{PE}_{11}$ portrays the efforts paid by the clients in the first month (if the efforts are recorded in monthly basis), which corresponds to the grid where it has been filled by the dark line in Fig 3 (a). The dark line here serves as an indicator which illustrates the participation of the specific party only, while the details of efforts such as cost are not provided. For some grids in Fig 3 (a) where there remains blank, the corresponding entries of PE (e.g. $\mathrm{PE}_{23}, \mathrm{PE}_{24}$, etc) keep as zero, representing that the specific professional does not involve in the project during the 'blank' period. By doing so, the matrix PE could help to document all the efforts of all professionals in a consistent manner for the whole project lifecycle. A proxy for the PE is the interim payments made by the client to different participants for services rendered. It is thus possible to collect the data for input efforts as shown in Fig. 3(a) by analyzing payment records. This means of data collection can be undertaken even after completion of a project.

By vertically aggregating all entries for each column (from 1 to $t$ ) in the Matrix PE (equation 1), where it can be denoted as $P E_{j}=\sum_{i=1}^{n} P E_{i j}$, the 'effort' at time $j$ applied to the project can be obtained. For example, $\mathrm{PE}_{1}$ demonstrates the aggregate efforts occurred in the first month (if the record is on monthly basis) of the project. By repeating this procedure for the BIM project and non-BIM project 
respectively, two sets of time-effort data are collected, defined in mathematical language as shown in Equations (2) and (3).

$$
\begin{array}{ll}
E=\left\{P E_{1}, P E_{2}, P E_{3}, \ldots \ldots, P E_{T}\right\} & \text { Equation (2) } \\
E^{\prime}=\left\{P E_{1}^{\prime}, P E_{2}^{\prime}, P E_{3}^{\prime}, \ldots \ldots, P E_{t}^{\prime}\right\} & \text { Equation (3) }
\end{array}
$$

where $E$ is the set of priced efforts data for the BIM project and $T$ is the corresponding time point; while $E^{\prime}$ denotes the set of priced efforts data for the non-BIM project, and $t$ is relevant time point.

\section{Step 2: Data processing through normalization}

In order to compare the time-effort distribution curves of BIM and non-BIM projects, it is necessary to identify two real-life projects, one with BIM implemented and the other without. To allow for meaningful comparison, ideally the two projects would be identical. Yet in the real world, as the cliché goes, "no two projects are exactly the same". There are many factors, such as the project manager's leadership and workers' craftsmanship, that make a project unique. This uniqueness can only be minimized so that the two sets of data are comparable, if not entirely identical. To this end, similar projects may be selected from the same company to allow for, at least, shared organizational culture, working capability, and so on.

Beyond this, construction projects very often have different site conditions, gross floor area (GFA), contract sums, procurement models, start dates, and so forth. Thus, it is necessary to 'normalize' the two data sets to reduce the impact of random factors and to make them comparable. The first step of this normalization is to discount the difference in GFA; the larger the GFA of a project, the more effort is likely to be spent. Thus, the two data sets in Equations (2) and (3) are divided by the GFA of the corresponding projects. Secondly, the impact of inflation should be deducted to allow for different start dates. By setting the earliest date as the baseline, the inflation index at each time point can be calculated from governmental statistics reports. The two data sets are now divided by the inflation index. As a result of this data processing, two sets of data on normalized priced efforts can be derived as shown in Equations (4) and (5). 


$$
\begin{array}{ll}
E N=\left\{\frac{P E_{1}}{G F A \times C P I_{1}}, \frac{P E_{2}}{G F A \times C P I_{2}}, \frac{P E_{3}}{G F A \times C P I_{3}}, \ldots . ., \frac{P E_{T}}{G F A \times C P I_{T}}\right\} & \text { Equation (4) } \\
E N^{\prime}=\left\{\frac{P E_{1}^{\prime}}{G F A^{\prime} \times C P I_{1}^{\prime}}, \frac{P E_{2}^{\prime}}{G F A^{\prime} \times C P I_{2}^{\prime}}, \frac{P E_{3}^{\prime}}{G F A^{\prime} \times C P I_{3}^{\prime}}, \ldots . ., \frac{P E_{t}^{\prime}}{G F A^{\prime} \times C P I_{t}^{\prime}}\right\} & \text { Equation (5) }
\end{array}
$$

where $E N$ denotes the set of normalized priced efforts data for the BIM project, GFA is the corresponding gross floor area, $T$ is the time point, and $C P I_{T}$ is the inflation index compared to the baseline at the time point $T$; while $E N^{\prime}$ denotes the set of normalized priced efforts data for the non-BIM project, $G F A^{\prime}$ is the corresponding gross floor area, $t$ is the time point, and $C P I_{t}^{\prime}$ is the inflation index compared to the baseline at the time point $t$.

In addition, as projects may not only start at different times but also vary in duration, the time point mentioned above should be also normalized. One common way to do this is to transfer the time point to the percentage of project completion (PPC) at that time point, which thus ranges from $0 \%$ to $100 \%$. That is, the specific time point is divided by the project duration. For example, if a project is to be completed in 24 months, the normalized time for the time point of the 6 th month is $25 \%$. As a result of this procedure, two sets of normalized time can be derived as shown in Equations (6) and (7).

$$
\begin{array}{ll}
T N=\{1 / L, 2 / L, 3 / L, \ldots \ldots, T / L\} & \text { Equation (6) } \\
t n=\{1 / l, 2 / l, 3 / l, \ldots \ldots ., t / l\} & \text { Equation (7) }
\end{array}
$$

where $T N$ is the normalized time data for the BIM project, $T$ is time point when the data was collected for the BIM project, and $L$ is the corresponding project duration; while $t n$ is the normalized time data for the non-BIM project, $t$ is the time point when data was collected from the non-BIM project, and $l$ is the corresponding project duration. By linking the normalized data of time and effort, the Equations (4) and (5) can be transformed into Equations (8) and (9).

$$
\begin{aligned}
& E N N=\left\{\frac{P E_{1 / L}}{G F A \times C P I_{1 / L}}, \frac{P E_{2 / L}}{G F A \times C P I_{2 / L}}, \frac{P E_{3 / L}}{G F A \times C P I_{3 / L}}, \ldots . ., \frac{P E_{T / L}}{G F A \times C P I_{T / L}}\right\} \text { Equation (8) } \\
& E N N^{\prime}=\left\{\frac{P E_{1 / l}^{\prime}}{G F A^{\prime} \times C P I_{1 / l}^{\prime}}, \frac{P E_{2 / l}^{\prime}}{G F A^{\prime} \times C P I_{2 / l}^{\prime}}, \frac{P E_{3 / l}^{\prime}}{G F A^{\prime} \times C P I_{3 / l}^{\prime}}, \ldots \ldots ., \frac{P E_{t / l}^{\prime}}{G F A^{\prime} \times C P I_{t / l}^{\prime}}\right\} \text { Equation (9) }
\end{aligned}
$$


where $E N N$ is the data set of normalized time-effort for the BIM project and $T / L$ is its PPC; while $E N N^{\prime}$ denotes the data set of normalized time-effort for the non-BIM project and $t / l$ is its PPC. Through the normalization procedures, the elements of equations (8) and (9) contain two sets of information: namely 'normalized effort' and 'time'. For the graphical demonstration in step 3, it is necessary to rewrite Equations (8) and (9) as Equations (10) and (11):

$$
\begin{aligned}
& E N N=\left\{\left(1, \frac{P E_{1 / L}}{G F A \times C P I_{1 / L}}\right),\left(2, \frac{P E_{2 / L}}{G F A \times C P I_{2 / L}}\right),\left(3, \frac{P E_{3 / L}}{G F A \times C P I_{3 / L}}\right), \ldots \ldots,\left(T, \frac{P E_{T / L}}{G F A \times C P I_{T / L}}\right)\right\} \text { Equation (10) } \\
& E N N^{\prime}=\left\{\left(1, \frac{P E_{1 / l}^{\prime}}{G F A^{\prime} \times C P I_{1 / l}^{\prime}}\right),\left(2, \frac{P E_{2 / l}^{\prime}}{G F A^{\prime} \times C P I_{2 / l}^{\prime}}\right),\left(3, \frac{P E_{3 / l}^{\prime}}{G F A^{\prime} \times C P I_{3 / l}^{\prime}}\right), \ldots . .,\left(t, \frac{P E_{t / l}^{\prime}}{G F A^{\prime} \times C P I_{t / l}^{\prime}}\right)\right\} \text { Equation (11) }
\end{aligned}
$$

where the elements in Equations (10) and (11) consist of two dimensional information. As such, it is straightforward to map each element of Equations (10) and (11) into a two-dimension coordinate system through plotting the normalized effort at the specific time accordingly, where horizontal axis is termed as time, vertical axis is denoted as normalized effort. From this point onwards, analysis is based on the datasets shown in Equations (10) and (11) rather than in Equations (2) and (3).

\section{Step 3: Depicting the time-effort distribution curves}

With normalized time-effort data, the distribution curve of a project can be depicted in the two-dimensional coordinate system for further analysis. Firstly, the time-effort distribution curves generated from the real-life projects can be compared with the theoretical curve proposed by MacLeamy (2004). In addition, the pattern of increased or saved effort can be revealed through comparison of BIM and non-BIM project time-effort distribution curves. Implications of the real-life time-effort distribution curves can further be explored, such as how they can inform the improved implementation of BIM by stakeholders.

\section{Case study}

\section{Data samples}

Two public housing projects in Hong Kong - one with BIM implemented and the other not - were selected for the empirical case study. Basic information on the two projects is summarized in Table 1. 
Both projects are high-rise, non-standard domestic buildings. The main frameworks of the projects were constructed using cast in-situ technologies while the rest, such as the slabs, walls, façade and kitchens used precast technologies. Both adopted a traditional design, bid, and build (DBB) procurement model. They are both located in Kowloon, Hong Kong, and thus presented similar site conditions for conduct of the AEC processes. Both projects were developed by the Hong Kong Housing Authority (HKHA), the government executive arm responsible for public housing development in Hong Kong. The BIM project has seen BIM implementation throughout the AEC processes. The non-BIM project, as its name indicates, had no BIM elements involved. The BIM project was still ongoing, being $85 \%$ complete when the data was collected in May 2013, while the non-BIM project was completed in that month.

Table 1. Basic information on the researched housing projects

\begin{tabular}{|l|l|l|}
\hline & BIM project & Non-BIM project \\
\hline Location/District & Kowloon & Kowloon \\
\hline Type of Building & Non-standard domestic building & Non-standard domestic building \\
\hline $\begin{array}{l}\text { Contract Sum (Foundation stage, } \\
\mathrm{HK} \$ \mathrm{~m})\end{array}$ & Not available & 102.343 \\
\hline $\begin{array}{l}\text { Contract Sum (Building Stage, } \\
\mathrm{HK} \$ \mathrm{~m})\end{array}$ & 384 & 505.300 \\
\hline Gross Site Area $\left(\mathrm{m}^{2}\right)$ & 12,000 & 10,188 \\
\hline Gross Floor Area $\left(\mathrm{m}^{2}\right)$ & 42,480 & 53,184 \\
\hline Starting Date & September 2008 & February 2007 \\
\hline Progress & $85 \%$ complete in May 2013 & Completed in May 2013 \\
\hline
\end{tabular}

An interview with the HA project manager was conducted to gain in-depth understanding of the implementation of BIM in the project. Specifically, the BIM model was used to cover three disciplines for the design stage of BIM project, including Architectural BIM model, Structural BIM model and site formation BIM model. For the Architectural BIM model, the HA would outsource the task of building an architectural BIM model to a consultant, who will develop and use BIM model to show the architectural elements such as architectural layout and works, internal and external walls and columns, 
rooms with area and finishing schedule. In so doing, it can help to improve the co-ordination and construction, but not for presentation.

As for the structural BIM, it is developed for the domestic block, landscape deck, covered walkways and all external works which shall contain all structural framing components. For example, footings and tie beams, in-situ beams, slabs and staircases, transfer beams and plates etc. Furthermore, the HA project team would hire a contractor to utilize BIM models to develop site formation elements such as boundaries of sub-soil geological units, topography and details of the newly formed slopes, retaining walls, debris resisting barrier and their associated slope surface protection measures, slope drainage channels systems including down pipes, sub-surface drainage layers, maintenance accesses and stabilization measures such as soil mails and tie-backs within the site boundary.

Within such scope of detail preparation work for the BIM project, the project manager reflected that the cost by using BIM models at the design stage in the building project may increase around 35\% 40\% comparing to that without BIM. In consequence, the effects of saving cost, if there are any, would appear in the construction stage. The following section would demonstrate the cost change through drawing its time-efforts curve.

\section{Data processing}

Following Step 1 as described in the methodology section, the innovative data collection vehicle (Fig. 3) was used to collect the priced efforts of the two projects. In Step 2, the datasets were normalized via division of the efforts by GFA and CPI. The BIM project was started in September 2008; as of May 2013, after 57 months, it was 85\% complete. The non-BIM project commenced in February 2007 and was fully completed in May 2013, after 76 months. The priced efforts comprise two main parts: the time sheet created by the HKHA when its in-house design teams undertook various tasks such as schematic design, engineering, and tendering, and the interim payment made by the HKHA to external stakeholders such as contractors and consultants. The in-house payment provides a detailed elaboration of efforts spent on a project by the in-house team. Although the team is within the HKHA 
as a statutory body, it actually operates based on market mechanism; efforts were recorded and priced, similar to other commercial companies do. The priced efforts of the two projects in each month were obtained by aggregating the in-house payment and the interim payment in each month. The interim payment was recorded by HKHA strictly according to the progress, which therefore reflects all relevant incurred costs at the recorded time.

Setting February 2007 as the baseline, the inflation index in each month was calculated using the CPI released by the Census and Statistics Department of Hong Kong Government. By following the methods described in Step 2, the priced efforts of the two projects were normalized with the respective GFA and the CPI. In addition, the time data of the two projects were normalized by following the approach described in Step 2.

\section{Depicting the time-effort distribution curves}

Using the normalized time-effort data, the time-effort distribution curves of the non-BIM and the BIM project were produced, as shown in Figures 4 and 5. The process involved links the normalized effort data points and plots them in the two-dimensional coordinate system. The vertical axis is the effort spent on each unit of the floor area (unit: $\mathrm{HKD} / \mathrm{m}^{2}$ ) and the horizontal axis is the progress of the project ranging from $0 \%$ to $100 \%$. To better understand how the efforts were distributed across AEC processes, the processes have been roughly divided into two stages: the design stage and the building stage. The design stage includes inception, feasibility study, foundation, design, engineering and bidding or, in other words, the architecture (A) and engineering (E) processes, while the building stage in Figures 4 and 5 is the construction (C) process. Through interviews with the project managers, it was found that the design stage of the BIM project lasted from September 2008 to June 2010, while that of the non-BIM project lasted from February 2007 to August 2009. 


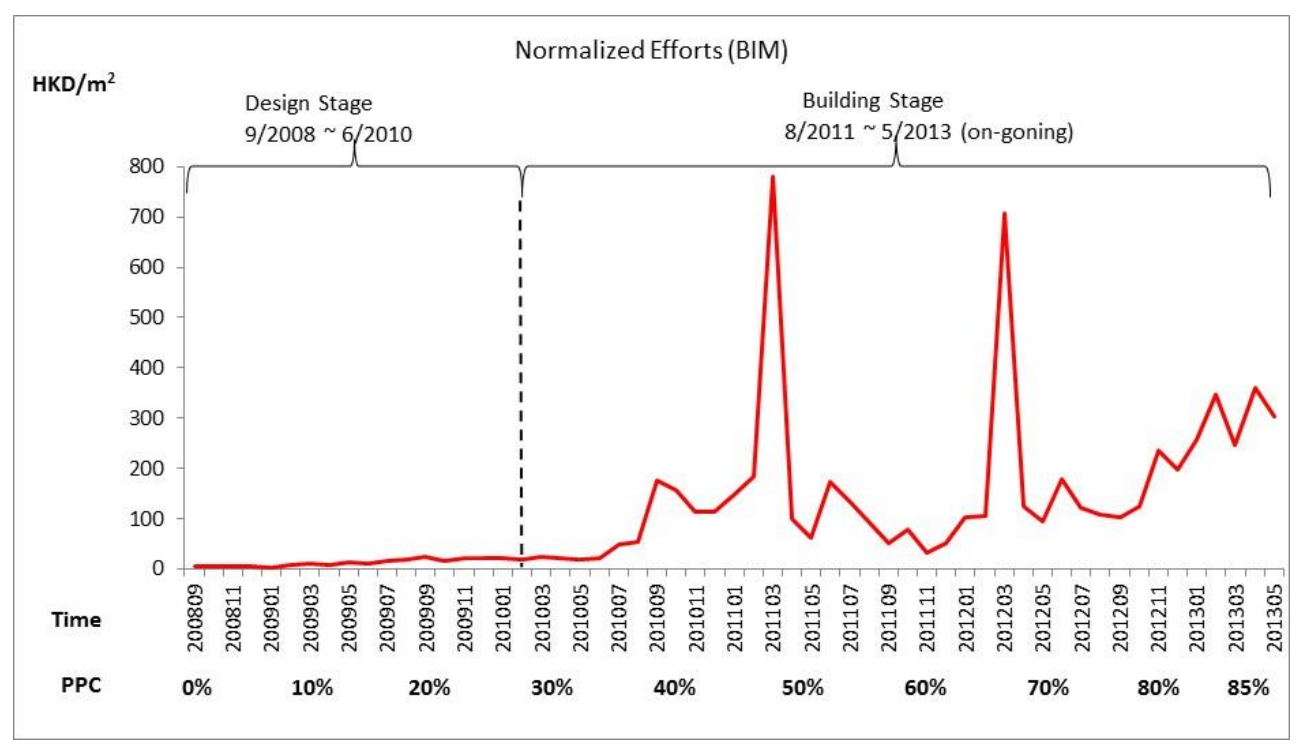

Fig. 4. Plotted time-effort distribution curve of the BIM project

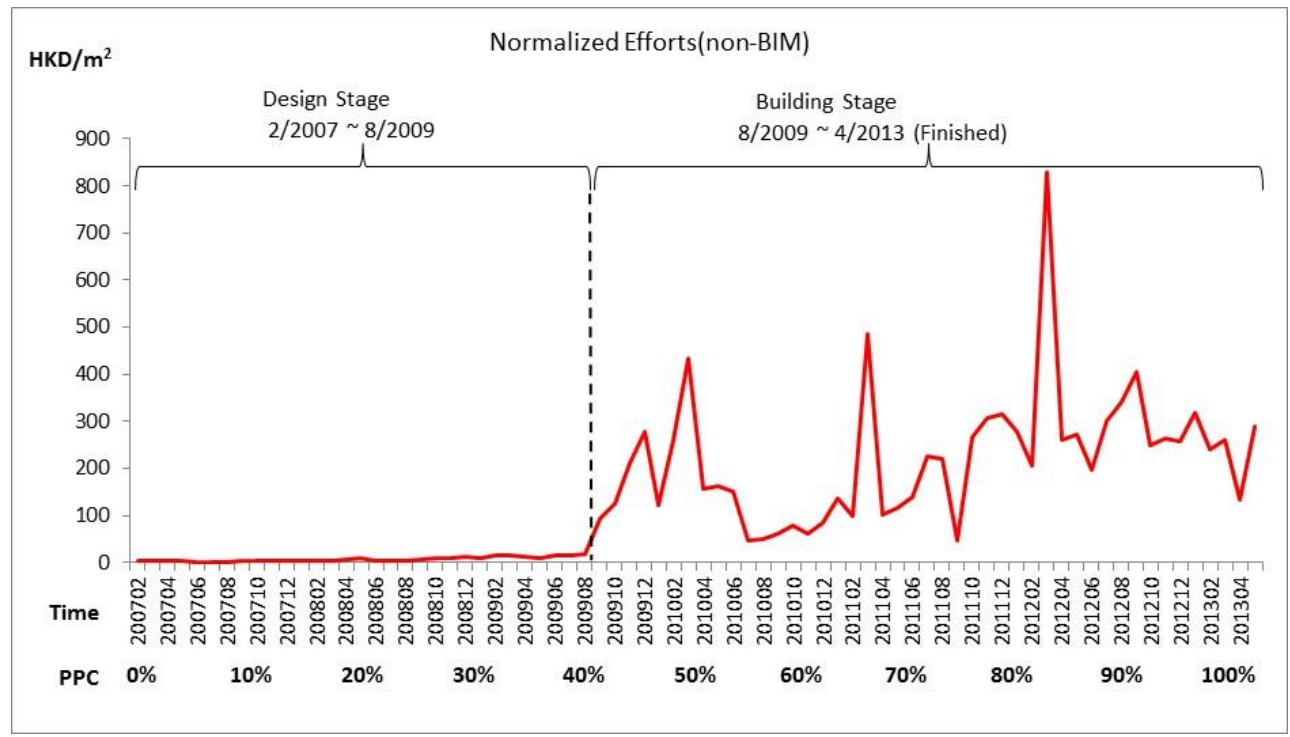

Fig. 5. Plotted time-effort distribution curve of the non-BIM project

\section{Analyses, findings, and discussion}

\section{General observations on the time-effort distribution curves}

In both Figures 4 and 5, there are many spikes on the curves, and the later the project stage, the more spikes there are. This is attributed to the payment system prevailing in the construction industry. Contractors are paid in arrears; normally at the end of one month, an interim payment to a contractor will be arranged to reimburse the contractor for the work undertaken.

One may also observe that the curves at the design stage in both projects are quite flat when compared 
to their counterparts at building stage. Indeed, the effort spent at design stage is often minuscule compared to the effort spent at the physical building stage which often involves huge material, labour, and plant input. Plotting the effort spent at the two project stages in the same two-dimensional coordinate system, it comes as no surprise that the curves at the design stage are flat and close to the horizontal axis.

At this juncture, it should be emphasized that MacLeamy (2004) emphasizes design effort only in his curves, suggesting that a small change in design effort can make a significant difference in the overall project. However, a closer look at the design effort distribution curves at the design stage does not yield any sense of similarity between the actual curves and MacLeamy's theoretical curves. This requires us to put the two curves on design efforts in the same two-dimensional coordinate system for comparison.

\section{Comparing the actual and theoretical time-effort distribution curves in $A \& E$ processes}

Fig. 6 shows the actual time-effort distribution curves of the real-life BIM and non-BIM projects at design stage. The smaller scale in the vertical axis makes the curves more contrasting to allow for better comparison. It can be seen from Fig. 6 that the first peak of normalized effort for the BIM project is $25.2 \mathrm{HKD} / \mathrm{m}^{2}$ at $\mathrm{PPC}$ of $19 \%$, the second is $24.02 \mathrm{HKD} / \mathrm{m}^{2}$ at $28 \%$, and the third is 21.84 $\mathrm{HKD} / \mathrm{m}^{2}$ at $33 \%$. The normalized design effort curve for the BIM project begins to decrease after it reaches the first peak at 19\%, although it still has two lower peaks after that. By contrast, there are four peaks of the normalized design effort curve for the non-BIM project: the fourth is $8.9 \mathrm{HKD} / \mathrm{m}^{2}$ at $21 \%$, the third is $13.56 \mathrm{HKD} / \mathrm{m}^{2}$ at $30 \%$, the second is $16.53 \mathrm{HKD} / \mathrm{m}^{2}$ at $34 \%$, and the first is 17.21 $\mathrm{HKD} / \mathrm{m}^{2}$ at $41 \%$. The value of the normalized effort for the non-BIM project increases with PPC and reaches its peak at the end of the design stage. Although the curves in Fig. 6 are not as smooth as MacLeamy (2004)'s theoretical curves (See Fig. 1), which may be a result of noise and the discrete form of the data, they do vividly show that the effort peak was shifted to an earlier stage with BIM implementation. Therefore, the theoretical time-effort distribution curves proposed by MacLeamy (2004) are supported by the two real-life cases. 


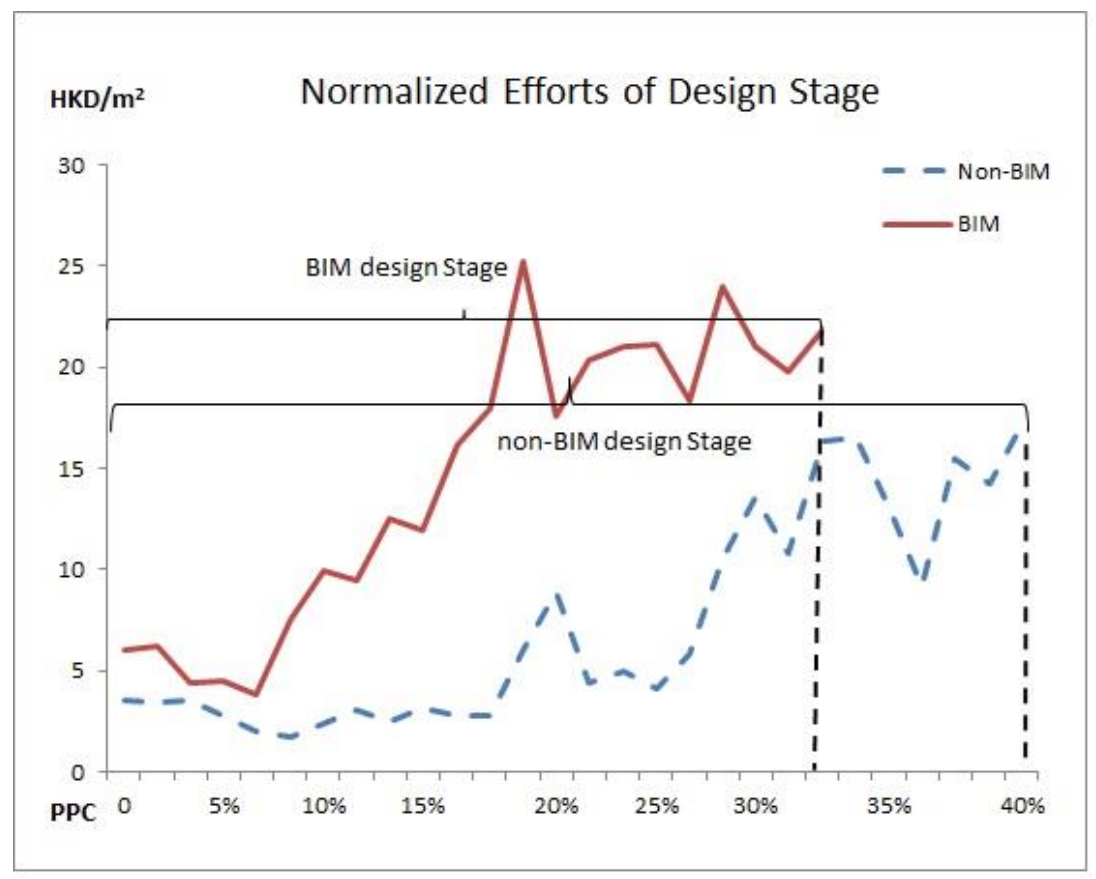

Fig.6. The time-effort distribution curve of BIM and non-BIM projects at the design stage

In addition, it can be seen from Fig. 6 that the design stage of the BIM project was proportionately briefer than that of the non-BIM project. For the BIM project, its design stage occupied just $33 \%$ of the project duration, while that of the non-BIM project occupied $41 \%$. This finding is echoed by previous research reporting that BIM is a useful tool for improving the efficiency of design, enabling easier access to check and revise the design scheme (e.g. Sacks and Barak, 2008; Jiang and Leicht, 2014). In addition, with the support of BIM, it is much easier to conduct quantity surveying which advances the progress of tendering and bidding (e.g. Grilo and Jardim-Goncalves, 2011). It is a fact that the design stage of a project is shortened by adopting BIM.

Nevertheless, the cost or, in other words, priced effort, incurred at the design stage of the BIM project is found to be larger than that of the non-BIM project. For better comparison, the S-curves of the two projects at the design stage are produced, as shown in Fig.7. At the end of the design stage of the BIM project, the aggregated normalized design effort is $320.59 \mathrm{HKD} / \mathrm{m}^{2}$, while that of the non-BIM project is $219.69 \mathrm{HKD} / \mathrm{m}^{2}$. This resonates with industrialists' concerns that BIM implementation will increase the design cost, which was also confirmed in the interview with the HA project manager. BIM 
implementation does incur extra cost at the design stage through investment in software, hardware and human resources. This extra cost is one of the biggest obstacles preventing the industry from adopting BIM on a wider scale (Li et al., 2009). However, it should be noted that the increased cost in software, hardware and training can be apportioned to other projects. Moreover, it is hoped that the increased cost at the design stage will be offset by the benefits brought by BIM to the building and facilities management stages. This encourages us to examine the S-curves of the two projects holistically in conjunction with their time-effort distribution curves as shown in Figures 4 and 5.

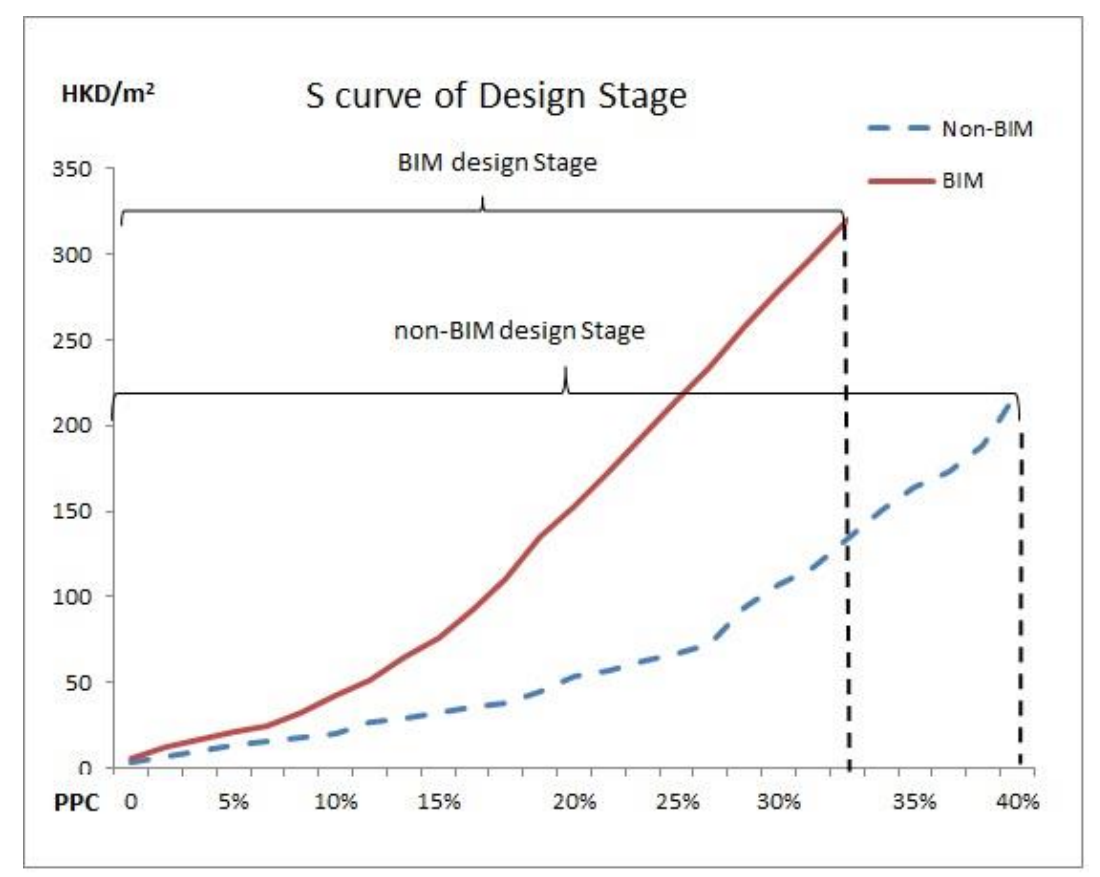

Fig.7. S-curves of the BIM and non-BIM projects at the design stage

\section{Comparing the actual time-effort distribution curves throughout the AEC processes}

As shown in the S-curves in Fig. 8, the aggregated normalized effort of the BIM project is larger than that of the non-BIM project at the design and early building stage. However, the aggregated normalized effort of the non-BIM project surpasses that of the BIM project from the PPC of about $80 \%$. At $85 \%$, the aggregated normalized effort of the BIM project is $6598.2 \mathrm{HKD} / \mathrm{m}^{2}$ while that of the non-BIM project is $7089.06 \mathrm{HKD} / \mathrm{m}^{2}$. Constrained by the data limit, it is difficult to compare the S-curve from $85 \%$ to $100 \%$. Yet, given that S-curve indicates the accumulated efforts at different times in a project, it is safe to conclude that the aggregated normalized effort of the BIM project would be 
smaller than that of the non-BIM project. The extra cost incurred by BIM implementation at the design stage is compensated for by the benefits it brings to the building stage. MacLeamy's (2004) theoretical suggestion that spending a little more on design efforts by implementing BIM will make a significant difference in the overall project performance is thus supported by the two real-life cases.

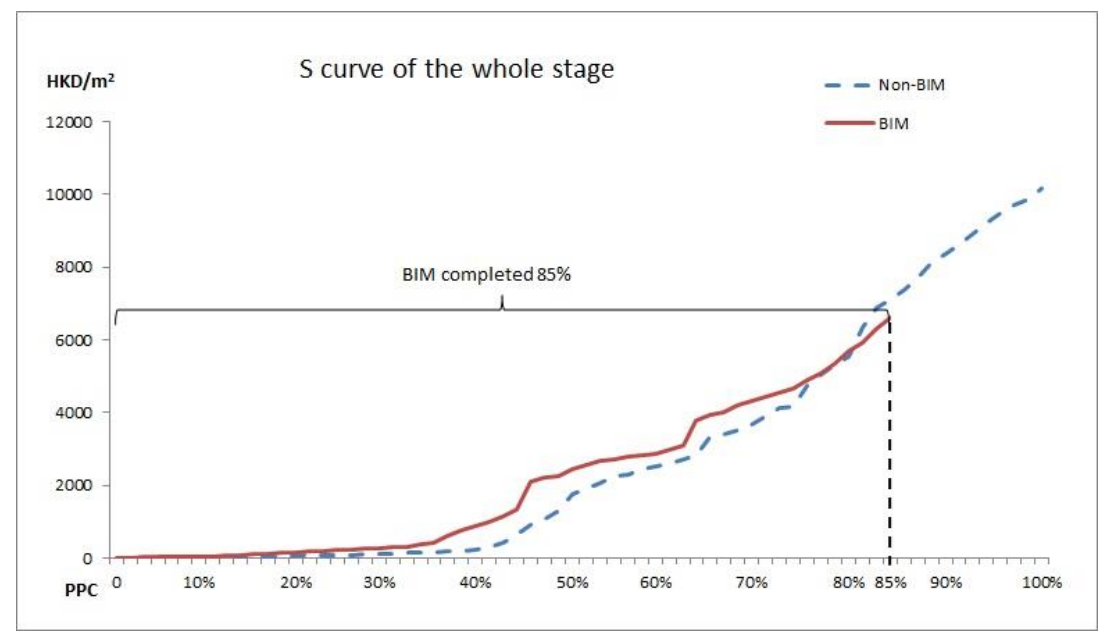

Fig. 8. S-curves of the BIM and non-BIM projects throughout the AEC stages

A closer look at the time-effort distribution curves of the two projects shows that the BIM project curve is more orderly than that of the non-BIM project at the building stage. From Fig. 4, it can be seen that there are two peaks of normalized effort for the BIM project at the building stage; the first is $779.57 \mathrm{HKD} / \mathrm{m}^{2}$ at the PPC of $46 \%$ and the second is $707.54 \mathrm{HKD} / \mathrm{m}^{2}$ at $64 \%$. From Fig. 5, it can be seen that there are three peaks of normalized effort for the non-BIM project at the building stage, the third is $433.78 \mathrm{HKD} / \mathrm{m}^{2}$ at the PPC of $50 \%$, the second is $486.15 \mathrm{HKD} / \mathrm{m}^{2}$ at $66 \%$, and the first is $829.27 \mathrm{HKD} / \mathrm{m} 2$ at $82 \%$. The BIM project has fewer fluctuations of normalized effort than the non-BIM project. This may be attributed to BIM's function of providing a better communication and management platform for a construction project. As quoted in Aranda-Mena et al. (2009), “...BIM implementation is all about project certainty. We know what we're designing, we know how much it's going to cost, we know how it's going to be built, and for us as a developer that is paramount to total success". Uncertainties and reworks are reduced through implementing BIM, therefore fewer ad hoc costs are incurred in the construction process. 
This was also confirmed in the interview with the HA project manager. In the BIM project, the contractor was required to prepare five high-resolution animations/walkthrough videos based on BIM. Each video lasts for five minutes in length to demonstrate the construction activities for site administration and planning aspects. By doing so, construction sequence can be rehearsed and different construction sequence would catch up with each other at platform with substantial level difference. Through these efforts, the project team was able to identify clashes and modify accordingly in the early stages, so as to minimize the risk of project delay. Through an accurate calculation of the soil amount to be cut and filled, the waste of resources was also reduced.

\section{Implications for BIM-enabled architecture, engineering, and construction processes}

Aranda-Mena et al.'s (2009) suggestion that a clear understanding of time-effort distribution curves would have direct implications for variations of fee structures is substantiated by this study. The fees should be skewed to the design stage to allow for the early involvement of all team members and open information sharing in detailing the design. The increased fees relating to BIM implementation will be recovered by the benefits it brings to the building stage, i.e., through reducing clash, design errors, and uncertainties. This finding is echoed by researchers (e.g. Sebastian, 2010; Chang and Howard, 2013) aiming to develop an economic framework for analyzing the incentive problems in BIM implementation.

The extra efforts spent on architecture and engineering processes through BIM implementation do not necessarily prolong the design stage. In fact, as suggested by the time-effort distribution curves, the design stage with BIM support occupied less time than the design stage without BIM support. The three-dimensional, virtual reality environment of BIM allows designers, after experiencing their initial learning curve, to better examine their design schemes. Design errors can be identified in advance, and design change can be implemented more easily. The shortened design stage as shown in the above time-effort distribution curves can thus be used to support promotion of wider BIM adoption in the construction industry. 
The above curves have demonstrated their usefulness in graphically examining time-effort distribution, and the different cost/benefit patterns caused by BIM implementation. By drawing the curves under different BIM implementation models (e.g. with integrated project delivery, or a holistic BIM) and examining their variations, it is possible to identify the strengths and weaknesses of each model. In this sense, the time-effort distribution curves are a useful tool for analysis of BIM implementation. It is therefore suggested that further studies are conducted to draw the curves in other real-life BIM cases and explore their implications for better BIM implementation.

\section{Conclusions}

Much has been said about the time-effort distribution curves introduced by MacLeamy, but little has been done to demystify them using real-life cases. Adopting a series of innovative approaches, this study produces and compares the actual time-effort distribution curves for a BIM project and a non-BIM project. The study proves that BIM implementation does incur extra expenses at the design stage, but the expenses will be offset at the building stage. The theoretical time-effort distribution curves proposed by MacLeamy are substantiated for the first time by the two real-life cases in this study. MacLeamy's theoretical suggestion that spending slightly more design effort will make a significant difference in the overall project performance is also supported by the two cases.

Implications arising from the time-effort distribution curves support the advancement of BIM adoption in architecture, engineering, and construction processes. The findings of this study, to a certain extent, uphold the argument that fee structures should be skewed to the design stage to fully exploit BIM's functionalities. More payment should be used for a full BIM model design. Further, rather than prolonging the design stage, BIM implementation can shorten the design stage by providing a platform for examination of design options, early involvement of all team members, and open information sharing. This finding should encourage users to adopt BIM more confidently. In addition, the time-effort distribution curves are found to be a handy graphical tool for examining cost/benefit patterns and the strengths/weaknesses underlying a BIM implementation model. However, it should be 
noticed that the data limitation in this case study such as the BIM project with $85 \%$ completion, normalization, neglecting the initial cost of rental or demolition, using cost to represent effort. Future studies can be conducted to investigate the time-effort distribution from other aspects, including using hourly data by type of staff to characterize effort, including the initial cost, normalization based on complexity or schedule, and collecting full data to conduct analysis. Moreover, further studies can be conducted to investigate which partner spend more efforts when implementing BIM and the process change and organization change caused by implementing BIM based on the time-effort distribution curve.

\section{Acknowledgement}

This study is jointly supported by the Small Project Fund (Project No.: 201109176228) at the University of Hong Kong, the Innovation and Technology Fund (Project No.: ITP/045/13LP) of the Innovation and Technology Commission (ITC), and the General Research Fund (Project No.: 17205614) of Hong Kong Research Grant Council (TGC). The authors would like to thank the dedicated BIM experts at HKHA including David Mak, Alex Ho, Christine Au, Stephen Yim, and Andrew Ngan for their enduring support of this research.

\section{References}

American Institute of Architects (AIA). (2010). Integrated Project Delivery: Case Studies. http://hga.com/sites/default/files/downloads/resources/ipd_casestudies_aiacc_final_010410_0.pdf (accessed on 28 ${ }^{\text {st }}$ August, 2014).

Aranda-Mena, G., Crawford, J., Chevez, A., and Froese, T. (2009). Building information modelling demystified: does it make business sense to adopt BIM?. International Journal of Managing Projects in Business, 2(3), 419-434.

Barraza, G. A., Back, W. E., and Mata, F. (2000). Probabilistic monitoring of project performance using SS-curves. Journal of Construction Engineering and Management, ASCE (March/April), $142-148$.

Chang, C.Y. and Howard, R. (2013). An Economic Framework for Analyzing the Incentive Problems 
in Building Information Modeling Systems. In: Proceedings of Academy of Management Annual Meeting, Philadelphia, USA 2014.

Chao, L. C., and Chien, C. F. (2009). Estimating project S-curves using polynomial function and neural networks. Journal of Construction Engineering and Management, 135(3), 169-177.

Cheng, Y.M., Yu, C.H., and Wang, H.T. (2011). Short-Interval Dynamic Forecasting for Actual S-curve in the Construction Phase. Journal of Construction Engineering and Management, 137(11), 933-941.

Construction Specifications Institute (2013). The CSI Project Delivery Practice Guide, Hoboken: John Wiley \& Sons, Inc.

Eastman, C., Teicholz, P., Sacks, R., and Liston, K. (2008). BIM Handbook, Hoboken: John Wiley \& Sons, Inc.

Engineering News (2012). Record MacLeamy Curve. http://enr.construction.com/images2/2012/06/fif.1.jpg (accessed on 28 ${ }^{\text {st }}$ August, 2014).

Grilo, A., and Jardim-Goncalves, R. (2011). Challenging electronic procurement in the AEC sector: A BIM-based integrated perspective. Automation in Construction, 20(2), 107-114.

Jiang, L., and Leicht, R. M. (2014). Automated Rule-Based Constructability Checking: Case Study of Formwork. Journal of Management in Engineering. DOI: 10.1061/(ASCE)ME.1943-5479.0000304.

Kaka, A. P. (1999). The development of a benchmark model that uses historical data for monitoring the progress of current construction projects Engineering. Construction and Architectural Management, 6(3), 256-266.

Li, H., Lu, W., and Huang, T. (2009). Rethinking project management and exploring virtual design and construction as a potential solution. Construction Management and Economics, 27(4), 363-371.

Lu, W., Peng, Y., Shen, Q., and Li, H. (2013). Generic Model for Measuring Benefits of BIM as a Learning Tool in Construction Tasks. Journal of Construction Engineering and Management, 139(2), 195-203.

Lu, W.S. and Li, H. (2011). Building Information Modeling and changing construction practices. Editorial for Automation in Construction, 20, 99-100. 
MacLeamy, P. (2004) Collaboration, integrated information and the project lifecycle in building

design, construction and operation. http://codebim.com/wp-content/uploads/2013/06/CurtCollaboration.pdf (accessed on 28 ${ }^{\text {st }}$ August, 2014)

Paulson, B. C. (1976). Designing to reduce construction costs. Journal of the Construction Division, 102(4), 587-592.

Sacks, R. and Barak, R. (2008). Impact of three-dimensional parametric modeling of buildings on productivity in structural engineering practice. Automation in Construction, 17(4), 439-449.

Sebastian, R (2010). Breaking through Business and Legal Barriers of Open Collaborative Processes based on Building Information Modelling (BIM). Proceedings of W113 - Special Track 18th CIB World Building Congress May 2010, Salford, UK.

Skitmore, M. (1998). A method for forecasting owner monthly construction project expenditure flow. Journal of Forecasting, 14, 17-34.

Smith, D. and Tardif, M. (2009). A strategic implementation guide for architects, engineers, constructor's, and real estate asset managers. Hoboken: John Wiley \& Sons.

Wu, W. and Issa, R. R. (2014). BIM Execution Planning in Green Building Projects: LEED as a Use Case. Journal of Management in Engineering. DOI: 10.1061/(ASCE)ME.1943-5479.0000314. 